Available online at GSC Online Press Directory

GSC Biological and Pharmaceutical Sciences

e-ISSN: 2581-3250, CODEN (USA): GBPSC2

Journal homepage: https://www.gsconlinepress.com/journals/gscbps

(RESEARCH ARTICLE)

\title{
Metformin hydrochloride delayed release tablets - a comparative dissolution profiles study
}

\author{
Bogantes-Molina Joselyn 1, Madrigal-Redondo German 1, 2,* Berrocal-Barrantes Lorena ${ }^{1,2}$ Chavarría-Rojas \\ Marianela ${ }^{1}$ Acuña-Amador Daniel Alejandro ${ }^{1,2}$ and Vargas-Zúñiga, Rolando ${ }^{1,2}$ \\ ${ }^{1}$ Pharmacy School, Universidad Latina of Costa Rica, San José, Costa Rica. \\ 2 Faculty of Pharmacy, University of Costa Rica, San José, Costa Rica.
}

Publication history: Received on 05 July 2019; revised on 26 August 2019; accepted on 30 August 2019

Article DOI: https://doi.org/10.30574/gscbps.2019.8.2.0119

\begin{abstract}
Multisource or generic drugs represent an important decrease in treatment cost for multiple diseases, which improves patient's medicine access. However, the therapeutic equivalence between original drugs (innovator) and generic or multisource drugs need to be demonstrated. Bioequivalence represents drug efficacy and higher security for patients, and it is considered as a fundamental factor for product commercialization. This work main objective was to make a comparison between the dissolution profiles of the original and multisource metformin hydrochloride tablets commercialized in Costa Rica. We used a validated analytical method to quantify metformin in dissolution medium, a phosphates buffered solution of $\mathrm{pH}(6.8 \pm 0.05)$. The obtained results demonstrated products interchangeability using the model-independent similarity factor $\left(\mathrm{f}_{2}\right)$ and difference factor $\left(\mathrm{f}_{1}\right)$ criteria.
\end{abstract}

Keywords: Metformin hydrochloride; Dissolution profiles; Multisource drugs; Tablets

\section{Introduction}

Medicine practice is the most common practice for health preservation or recovery [1]. According to the World Health Organization (WHO) drug access is considered a fundamental human been right [2,3]. Costa Rica's public health system, the Caja Costarricense de Seguro Social (CCSS), invests an important amount of its funds for drug acquisition. During 2011 alone, the institution spent more than $\$ 100000$ million colons, roughly $\$ 200000$ USD, in the purchase and distribution of about 71 million different medicines [4]. This is an example of why medicines are considered as an important and highly used health-care supply, and also, it explains the strict regulation imposed by the public health systems around the World. [5].

Generic drugs, also known as multisource drugs, are a very good option to treat both acute and chronic diseases because of its lower cost compared to the innovative drugs. The costs reduction in benefits both the patients and the public health system $[2,4,6]$.

It is required that generic medicines have, statically speaking, the same characteristics of innovator product, they must be identical in terms of quality, efficacy, security, pharmaceutical dosage form, dose, administration route and performance characteristics [7, 8]. Bioequivalence studies main objective is to establish a comparison between the generic product and the innovative product. The term bioequivalence refers to the absence of a significant difference in the rate and extent in which the active pharmaceutical ingredient (API) becomes available at the drug site of action when it is administered in the same dose and under similar conditions, in equivalent pharmaceutical dosage forms [7].

\footnotetext{
${ }^{*}$ Corresponding author

E-mail address: generacionlcr96@gmail.com
}

Copyright (C) 2019 Author(s) retain the copyright of this article. This article is published under the terms of the Creative Commons Attribution Liscense 4.0 
To demonstrate interchangeability between the innovator and the multisource drug, the first choice is to carry out in vivo bioequivalence studies. However, regulatory authorities like FDA and EMA, allow in vitro testing to demonstrate therapeutic equivalence only in a specific group of drugs. It is a way to decrease clinical studies execution, which represents an important cost reduction in drug development [8].

In vitro tests objective is to study the drug release characteristics and kinetics of an oral pharmaceutical dosage form. These tests consist of the dissolution profile comparison, which quantifies the dissolved amount of API across different times, under specific, controlled and validated conditions of both innovator and generic drugs. Similarity factor $\left(\mathrm{f}_{2}\right)$ is used for the comparison between reference and test products. This factor is a measure of the similarity, expressed as a percentage of dissolved API between the dissolution curves of both medicines. The afford mentioned studies award the therapeutic equivalence documentation between innovative and generic drug. It is important to remind that innovative drug is used as a reference product because clinical trials have demonstrated its efficacy, quality, and security [2, 8, 9, $10,11]$.

Metformin is an oral antidiabetic drug that belongs to the biguanide pharmacological group and it is used as a first-line treatment in type II Diabetes Mellitus [12]. Metformin is highly water soluble but, has a limited intestinal absorption. Metformin absorption process is dose-dependent, saturable, active and incomplete; it is carried out by cationic organic transporters. According to the BCS, metformin can be considered as a Class III, a high-solubility and low-permeability drug [13].

As a first-line treatment, oral metformin hydrochloride tablets are prescribed for a large number of patients who use the CCSS services. For this reason, it was decided to study the interchangeability between the innovator product and the multisource product, distributed by the CCSS Institution.

The main objective of this work was to analyze and study the dissolution profiles of different metformin hydrochloride tablets. The study compares the generic product against the reference product. A validated analytical method was used to quantify metformin hydrochloride in the dissolution medium using UV spectrophotometry.

\section{Material and methods}

\subsection{Materials}

Both the reference product and the multisource product, were enteric film-coated tablets with 500 mg of metformin hydrochloride. The reference product was Glisulin ${ }^{\circledR} 500 \mathrm{mg}$ tablets (Lot Number M70454) and the generic product was Metformin hydrochloride $500 \mathrm{mg}$ tablets distributed by CCSS during January - May 2018 (Lot Number E0796).

Metformin hydrochloride reference standard was purchased from Sigma Aldrich. All chemicals were analytical grade reagents and distilled purified water was used in all the tests.

\subsection{In vitro dissolution test}

Dissolution test was carried out on both products using a dissolutor Hanson Research, USP Apparatus 1 (baskets) was programmed to operate at 100 r.p.m. and under $(37 \pm 0.5)^{\circ} \mathrm{C}$.

Testing was conducted by adding $1000 \mathrm{~mL}$ of dissolution medium, a phosphates buffered solution $\mathrm{pH}(6.8 \pm 0.05)$ in each apparatus vessel. Once the dissolution medium reaches the constant temperature $(37 \pm 0.5){ }^{\circ} \mathrm{C}$, a metformin hydrochloride tablet was placed in each vessel and the test-time count began. Samples of $10 \mathrm{~mL}$ were taken at 5, 10, 15 and 30 minutes without volume replenishing of dissolution medium removed.

The samples were filtered using a $0.45 \mu \mathrm{m}$ pore filter. The filtrated solutions were diluted (1:500) using the phosphates buffered solution $\mathrm{pH}(6.8 \pm 0.05)$. The samples were measured using UV spectrophotometry at the maximum absorption wavelength $(233 \mathrm{~nm})$. The analytical method to quantify metformin was previously validated.

Dissolution profiles were obtained by evaluation of 12 dosage units of each product, the reference and test product. Dissolution profile analysis was carried out using the difference factor $\left(\mathrm{f}_{2}\right)$ and the similarity factor $\left(\mathrm{f}_{2}\right)$. The relative standard deviation of each sample time was calculated. 


\subsection{Dissolution kinetics}

The dissolution profiles of both products were used to determinate the mathematical model that best describes the dissolution kinetics. The mathematical models considered were Weibull model, Higuchi model, cube root model, first and zero order models. Correlation coefficient $\left(\mathrm{r}^{2}\right)$ analysis was calculated to establish the best mathematical model.

\subsection{Statistical analysis}

The statistical analysis was done using the Microsoft Office Excel 365 v. 1809 software.

\section{Results and Discussion}

Metformin is an oral anti-hyperglycemic drug that has been used as the first line in the management of Diabetes Mellitus type II. Metformin has high water solubility, but membranes permeability is limited. Hence, it is classified as a Class III drug, according to BCS $[12,13]$. The absorption process of drugs that belongs to this group is limited by its permeability, and it is dependent on biopharmaceutical and physiological factors. Because this reason, it has been suggested the possibility of executing in vitro equivalence studies to the Class III drugs [14].

The relationship between in vitro dissolution and in vivo absorption of metformin has been studied. This analysis showed that it was observed that controlled release tablets Glucophage ${ }^{\circ}$-Delayed release with a $100 \%$ drug dissolution, has equivalent bioavailability to an aqueous metformin solution. This can be explained by metformin absorption kinetics is governed by drug permeability, and not by the drug liberation process [14].

In this work, the dissolution profiles of two metformin hydrochloride $500 \mathrm{mg}$ tablets were evaluated. Currently, neither WHO nor the Health Department from Costa Rica has defined a reference product to metformin hydrochloride tablets. However, it is important to consider that the first drug commercialized in the United States as metformin hydrochloride tablets were under the brand Glucophage $®$, from Lipha Pharmaceuticals, nowadays Merck. Furthermore, in 1995, Merk was the first pharmaceutical laboratory in commercialized Glucophage $₫$ in Costa Rica [15]. For this reason, Glisulin $₫$ from Merck Laboratories was chosen as the reference product to the dissolution profile comparison. The test product was the drug distributed by CCSS.

Both, the reference product and the test product were enteric film-coated tablets. The "Guía Técnica para la Presentación y Evaluación de Estudios de Perfiles de Disolución del Ministerio de Salud de Costa Rica" (the technical guide for the presentation and evaluation of dissolution profile studies of the Costa Rica's Health ministry) indicate that enteric film-coated products must be tested only in a phosphate buffer dissolution medium. [16]

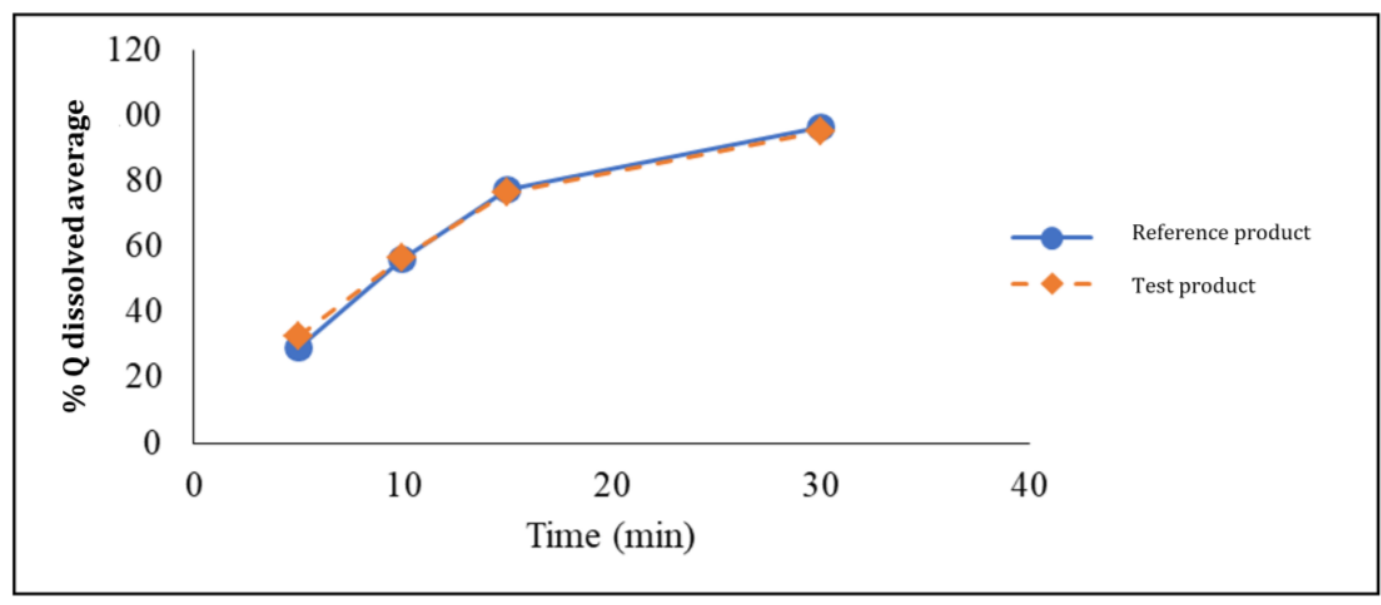

Figure 1 Metformin dissolution profile graphics comparison for the reference and test products in the dissolution medium

The comparative dissolution profile between reference and multisource product are shown in Figure 1 . At 30 min of the test beginning, both products reached almost $100 \%$ of drug dissolved, the reference product reached $97 \%$ and the multisource product a $95 \%$ (Table 1). On the other hand, at $15 \mathrm{~min}$, the amount of drug dissolved was lower than $85 \%$, which means that it is necessary for the statistical evaluation using the independent mathematical model, calculating $\mathrm{f}_{1}$ and $\mathrm{f}_{2}$. 
Table 1 Compared average dissolved percentage of metformin hydrochloride by time for the reference and test products in the dissolution medium.

\begin{tabular}{lllll}
\hline Time (min) & $\begin{array}{l}\text { Reference product } \\
\text { \% Q } \\
\text { dissolved } \\
\text { average }\end{array}$ & $\begin{array}{l}\text { Relative standard } \\
\text { deviation (\%) }\end{array}$ & $\begin{array}{l}\text { Test product } \\
\text { \% Q } \\
\text { dissolved } \\
\text { average }\end{array}$ & $\begin{array}{l}\text { Relative standard } \\
\text { deviation (\%) }\end{array}$ \\
\hline 5 & 29 & 17.28 & 32 & 3.86 \\
10 & 56 & 7.87 & 57 & 3.01 \\
15 & 78 & 9.77 & 77 & 2.08 \\
30 & 97 & 1.46 & 95 & 0.76 \\
\hline
\end{tabular}

The obtained results from $f_{1}$ and $f_{2}$ analysis are shown in Table 2. $f_{1}$ value was higher than zero, but smaller than $f_{2}$, indicating the difference absence among both dissolution profiles. the $f_{2}$ value was between the established range $(50-$ 100), which means the dissolution profile similarity [9].

Table $2 \mathrm{f}_{1}$ and $\mathrm{f}_{2}$ statistical evaluation

\begin{tabular}{ll}
\hline $\mathbf{f}_{\mathbf{1}}$ & $\mathbf{f}_{\mathbf{2}}$ \\
\hline 0.3856 & 97.58 \\
\hline
\end{tabular}

The relative standard deviation in each sample time was an evaluated statistical parameter. In the first sample, the value must be below $20 \%$, and in the other sample times, the relative standard deviation value must be smaller than 10 $\%$. In Table 1 , should be observed that both products met the established criteria.

Dissolution kinetics were studied from the dissolution profiles data. The degree of adjustment of the different mathematical models (Weibull, Higuchi, cube root, first order, and zero order) was evaluated using the correlation coefficient information. The analysis allows affirming that the first order model describes the dissolution process in both products, reference and multisource (Table 3). In Figure 2 and Figure 3 is shown the dissolution kinetics behavior for the reference product and test product, respectively.

Table 3 Dissolution constant and $\mathrm{r}^{2}$ data for kinetics dissolution determination of metformin in the dissolution medium

\begin{tabular}{|c|c|c|c|c|c|c|c|c|c|c|}
\hline \multirow{2}{*}{ Product } & \multicolumn{2}{|c|}{ Zero-order } & \multicolumn{2}{|c|}{ First order } & \multicolumn{2}{|c|}{ Cubic root } & \multicolumn{2}{|c|}{ Higuchi } & \multicolumn{2}{|l|}{ Weibull } \\
\hline & $\mathrm{r}^{2}$ & $\mathrm{~K}_{0}$ & $r^{2}$ & $\mathrm{~K}_{1}$ & $r^{2}$ & $\mathrm{~K}_{3}$ & $r^{2}$ & $\mathrm{~K}_{\mathrm{H}}$ & $\mathrm{r}^{2}$ & $\mathrm{~K}_{\mathrm{w}}$ \\
\hline Reference & 0.8084 & 12.4944 & 0.9972 & -0.1221 & 0.8084 & -4.1648 & 0.9152 & 17.7502 & 0.8623 & -1.6768 \\
\hline Multisource & 0.8221 & 11.6480 & 0.9981 & -0.1046 & 0.8221 & -3.8827 & 0.9244 & 95.4105 & 0.8846 & -1.4489 \\
\hline
\end{tabular}




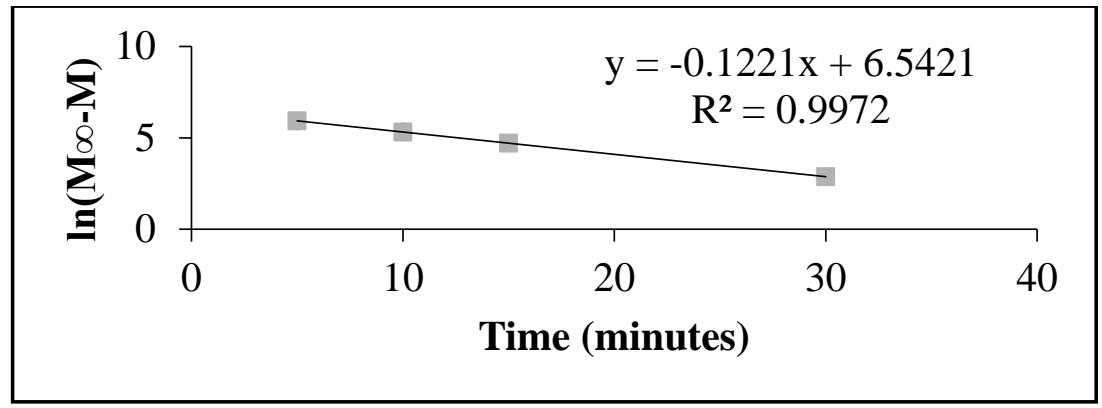

Figure 2 Reference product dissolution kinetics in dissolution medium graphical comparison

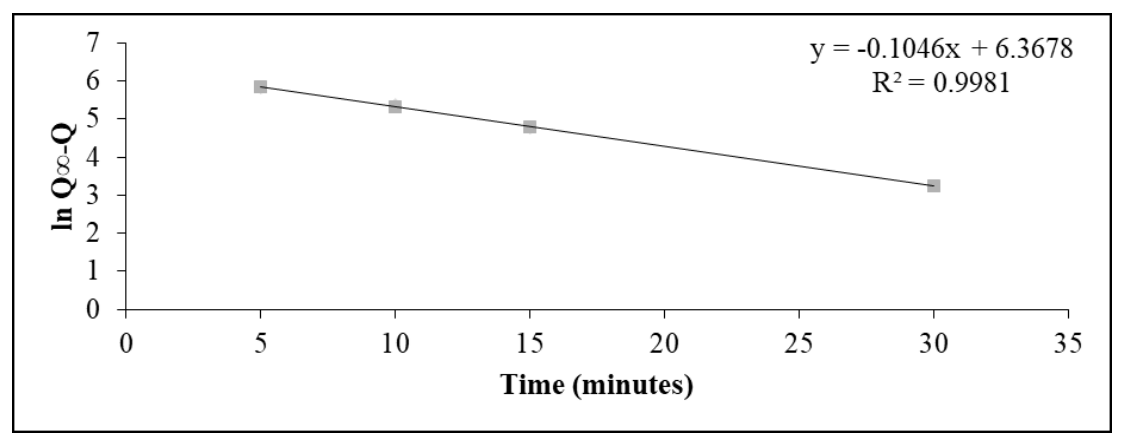

Figure 3 Test product dissolution kinetics in dissolution medium graphical comparison

\section{Conclusion}

The dissolution profile comparison using $\mathrm{f}_{1}$ and $\mathrm{f}_{2}$ factors shows the similarity between the multisource product and the reference product, both of them enteric film-coated metformin hydrochloride $500 \mathrm{mg}$ tablets. In addition, dissolution kinetics in both products is described by a first order model. Finally, considering all the evidence and experimental observations, the similarity among both products is demonstrated, which allows the possibility to consider their interchangeability.

\section{Compliance with ethical standards}

\section{Acknowledgments}

We are thankful to the Pharmacy School and the Basic Sciences Department, Universidad Latina of Costa Rica, San José, Costa Rica for providing facility to carry out present work.

\section{Disclosure of conflict of interest}

No conflict of interest exist.

\section{References}

[1] Sibaja MA. (2014). Psychosocial characterization of medication consumption in Costa Rica. Reflections Magazine, 93 (2), 55-65.

[2] Saavedra I, Iturriaga V, Ávila L and Quiñones L. (2011). Bio-exemption studies (in vitro) to establish equivalence of medications. Cuad Méd Social (Chile), 52 (2), 66-79.

[3] OMS. (2002). Guidance on the selection of comparator pharmaceutical products for equivalence assessment of interchangeable multisource (generic) products. World Health Organization.

[4] CCSS. (2012). Medicines. Wellness Magazine, 43, 8 - 98. 
[5] Pereira-Vega Z. (2016). Supply and demand of therapeutic equivalence studies (in vitro and in vivo) of medicines in Costa Rica. Ongoing Technology, 29 (1), 18-27.

[6] Segura L. (2017). Generic drugs: their economic importance in public health systems and the need for in vitro studies to establish their bioequivalence. Acting Thought, 108-120.

[7] Jalali RK and Rasaily D. (n.d.). Generic Drug and Bioequivalence Studies. Pharmaceutical Medicine and Translational Clinical Research. Elsevier.

[8] Samaniego J and Arias G. (2016). Qualification of the in vitro pharmaceutical equivalence by the HPLC methodology of four medications containing paracetamol, chlorphenamine maleate and phenylephrine hydrochloride tablets. Rev. Soc. Quim Peru., 82 (4).

[9] FDA. (2015). Waiver of In vivo Bioavailability and Bioequivalence Studies for Immediate-Release Solid Oral Dosage Forms Based on a Biopharmaceutics Classification System. Maryland: Center for Drug Evaluation and Research.

[10] Marroum PJ. (2014). History and Evolution of the Dissolution Test. Dissolution Technologies, 11-16.

[11] Tam Paiba C. (2013). Comparison of dissolution profiles of Amlodipine in 5 mg multifuente tablets and the innovative product. Trujillo, Peru.

[12] Homšek I, Parojcic J, Dacevic M, Petrovic L and Jovanovic D. (2010). Justification of metformin hydrochloride biowaiver criteria based on bioequivalence study. Arzneimittelforschung, 60(09), 553-559.

[13] Zhou M, Xia L q and Wang, J. (2007). Metformin transport by a newly cloned proton-stimulated organic cation transporter (plasma membrane monoamine transporter) expressed in human intestine. Drug Metabolism and Disposition, 1956-1962.

[14] Cheng C, Yu L, Lee H, Yang C, Lue C and Chou C. (2004). Biowaiver extension potential to BCS Class III high solubility - low permeability drugs: bridging evidence for metformin immediate-release tablet. European Journal of Pharmaceutical Sciences, 297 - 304.

[15] Bailey C. (2017). Metformin: historical overview. Birmingham: Springer-Verlag Berlin Heidelberg.

[16] Ministry of Health of Costa Rica. (s.f.). Validation Guide of Analytical Methods. Saint Joseph.

\section{How to cite this article}

Bogantes-Molina J, Madrigal-Redondo G, Berrocal-Barrantes L, Chavarría-Rojas M, Acuña-Amador DA and VargasZúñiga R. (2019). Metformin hydrochloride delayed release tablets - a comparative dissolution profiles study. GSC Biological and Pharmaceutical Sciences, 8(2), 113-118. 